Article

\title{
Analysis of Cyanogenic Compounds Derived from Mandelonitrile by Ultrasound-Assisted Extraction and High-Performance Liquid Chromatography in Rosaceae and Sambucus Families
}

\author{
Roberto Rodríguez Madrera * (D) and Belén Suárez Valles
}

Citation: Rodríguez Madrera, R.; Suárez Valles, B. Analysis of Cyanogenic Compounds Derived from Mandelonitrile by

Ultrasound-Assisted Extraction and High-Performance Liquid

Chromatography in Rosaceae and Sambucus Families. Molecules 2021 26, 7563. https://doi.org/10.3390/ molecules 26247563

Academic Editors: Gregory Chatel and Jose V. Garcia-Perez

Received: 11 November 2021 Accepted: 12 December 2021 Published: 14 December 2021

Publisher's Note: MDPI stays neutral with regard to jurisdictional claims in published maps and institutional affiliations.

Copyright: (c) 2021 by the authors. Licensee MDPI, Basel, Switzerland. This article is an open access article distributed under the terms and conditions of the Creative Commons Attribution (CC BY) license (https:/ / creativecommons.org/licenses/by/ $4.0 /)$.
Área de Tecnología de los Alimentos, Servicio Regional de Investigación y Desarrollo Agroalimentario (SERIDA), 33300 Villaviciosa, Asturias, Spain; mbsuarez@serida.org

* Correspondence: rrodriguez@serida.org

Abstract: An analytical method for extraction and quantitative determination of amygdalin, prunasin, and sambunigrin in plant material is described. The method is based on extraction with high-power ultrasound (UAE), with acidified water as solvent and quantification by HPLC-DAD. The best extraction conditions were: $80 \%$ sonication amplitude, 55 s extraction time, $70 \%$ duty cycle, $0.1 \mathrm{~g}$ sample mass, and $10 \mathrm{~mL}$ acidified water $(0.1 \%$ perchloric acid). Once developed, the method was validated in terms of accuracy and precision. Good linearity was obtained, with correlation coefficients exceeding 0.999 and the quantification limits ranged from $2.2 \mu \mathrm{g} / \mathrm{g}$ (amygdalin) to $9.6 \mu \mathrm{g} / \mathrm{g}$ (sambunigrin). The accuracy (recovery study) ranged between 90 and 104\% and the reproducibility of the method was always $<2.3 \%$ (RSD). Special attention should be paid to the ratio sample/solvent in samples with potential $\beta$-glucosidase activity to avoid degradation of the cyanogenic glycosides (CNGs). The proposed method was used to evaluate the content of CNGs in kernels of Prunus genera, apple seeds, apple pomace, and different plant materials of Sambucus nigra.

Keywords: cyanogenic compounds; mandelonitrile; amygdalin; prunasin; sambunigrin; HPLC-DAD; UAE; method validation

\section{Introduction}

Cyanogenic glycosides (CNGs) are a group of secondary metabolites of the plant kingdom involved in different functions, such as the transport and turnover of nitrogen and plant development [1].

CNGs are formed by an aglycone, which contains in its structure a nitrile group with a hydroxyl group in the alpha position, to which sugar is attached (generally a monosaccharide or a disaccharide). CNGs release hydrogen cyanide (HCN) in the presence of $\beta$-glucosidase and $\alpha$-hydroxynitrile lyase enzymes [2] in a process known as cyanogenesis [3]. HCN is a highly toxic compound and, therefore, the presence of CNGs is considered as part of the defense system of plants against attack by herbivores [4].

The European Food Safety Authority (EFSA) has carried out an exhaustive study on the identification and characterization of the risks and health hazards of cyanide [5]. This study highlights that cyanide is of high acute toxicity in humans. The lethal dose is reported to be 0.5 to $3.5 \mathrm{mg} / \mathrm{kg}$ of body weight. In Europe, the presence of cyanide in food, beverages, and additives is regulated by various standards [6-8]. A maximum level of $\mathrm{HCN}$ of $50 \mathrm{mg} / \mathrm{kg}$ has been established in nougat, marzipan or their substitutes or similar products, $5 \mathrm{mg} / \mathrm{kg}$ in canned pitted fruits and $35 \mathrm{mg} / \mathrm{kg}$ and a maximum HCN content of $7 \mathrm{~g} / \mathrm{hL}$ at $100 \%$ volume alcohol in fruit marc brandy and stone fruit brandy. Cyanogenic glycosides are mentioned in the legislation of some countries, such as the United Kingdom [9], Germany [10], Australia, and New Zealand [11]. 
Due to their potential toxicity, several studies have focused on the presence of CNGs in different plants, and they have been reported in over 2500 plant species [3,12]. CNGs are found in different parts of plants (seeds, leaves, stems, fruits) and are derived mainly from the amino acids tyrosine, valine, leucine, isoleucine, and phenylalanine [13].

In this regard, the mandelonitrile derivatives, naturally synthesized from phenylalanine, are one of the most widespread groups of CNGs. Thus, amygdalin or (R)mandelonitrile 6-O- $\beta$-D-gentiobioside and R-prunasin or (R)-mandelonitrile $\beta$-D-glucoside have been detected in seeds and kernels of members of the Rosaceae family, such as apple, almond, cherry, apricot, and many others [14-16]. On the other hand, sambunigrin or S-prunasin is a major cyanogenic compound in the leaf of Sambucus nigra, and it is present in other edible parts of the species [17].

It is possible to determine the total content of CNGs in plant samples by indirect methods, such as the picrate method [18], in which, after hydrolysis, the total HCN content is estimated. Cho et al. [19], however, estimated the total HCN content by ion chromatography.

The analytical methods described in the literature to quantify CNG from mandelonitrile usually employ water, methanol or their mixtures, and different extraction systems such as Soxhlet extraction, solid-phase extraction, ultrasound bath or solid-liquid extraction assisted by microwaves [1,2,14,17,20-22] during extraction periods that may last for $24 \mathrm{~h}$. The diverse chemical nature of cyanogenic glycosides means that the extraction and analysis of individual compounds can be difficult and furthermore, degradation can be rapid under appropriate conditions [16].

Ultrasound-assisted extraction (UAE) is a green alternative increasingly employed for the recovery of biomolecules in plant material. The ultrasonic waves generate pressure and cavitation, causing the rupture of the plant cells, which facilitates the extraction of the molecules of interest. Ultrasonic probes are designed to be immersed in the sample, and deliver the ultrasonic intensity directly to the liquid sample, which enhances the extraction yields and reproducibility and reduces the extraction time [23]. Compared with other methods, UAE is a fast technique, which is of particular interest in order to avoid the hydrolysis of the CNGs.

Extracts containing CNG are usually analyzed by reverse phase HPLC with UV-Vis detectors [16], HPLC-MS [21], or tandem HPLC-DAD-MS [17]. The separation of the R and $S$ epimers has been found to be one of the main difficulties of these methods, for which reason some authors have proposed the use of chiral phases [24].

The objective of this work has been the development and validation of an analytical method for the quantitative determination of the main cyanogenic derivatives of mandelonitrile (amygdalin, prunasin, and sambunigrin) by means of HPLC/DAD. UAE conditions have been optimized by using response surface methodology. Analytical parameters, such as linearity, limits of detection, quantification, precision, and accuracy were estimated. The proposed method has been used to evaluate the content of CNGs in kernels of Prunus genera, apple seeds, apple pomace, and different plant materials of Sambucus nigra.

\section{Results and Discussion}

\subsection{Chromatographic Separation and Identification}

The optimization of chromatographic conditions was carried out with extracts obtained according to the preselection of extraction conditions subsection.

One of the main difficulties in the analysis of cyanogenic derivatives of mandelonitrile is the separation of the diastereoisomers prunasin and sambunigrin from one another. To this end, the conditions employed by Bolarinwa et al. [16] were used as the point of departure, and a column temperature range of between 25 and $40{ }^{\circ} \mathrm{C}$ was studied. The best separation conditions were obtained at $25^{\circ} \mathrm{C}$, in an isocratic mode with a mobile phase consisting of $25 \%$ methanol in water at a flow of $1.0 \mathrm{~mL} / \mathrm{min}$. Figure 1 displays typical chromatograms of a mixture of standards and different extracts containing the analytes of 
interest. As seen in Figure 1, the three peaks are well separated, with a resolution $>2.0$ in the case of the prunasin isomers.
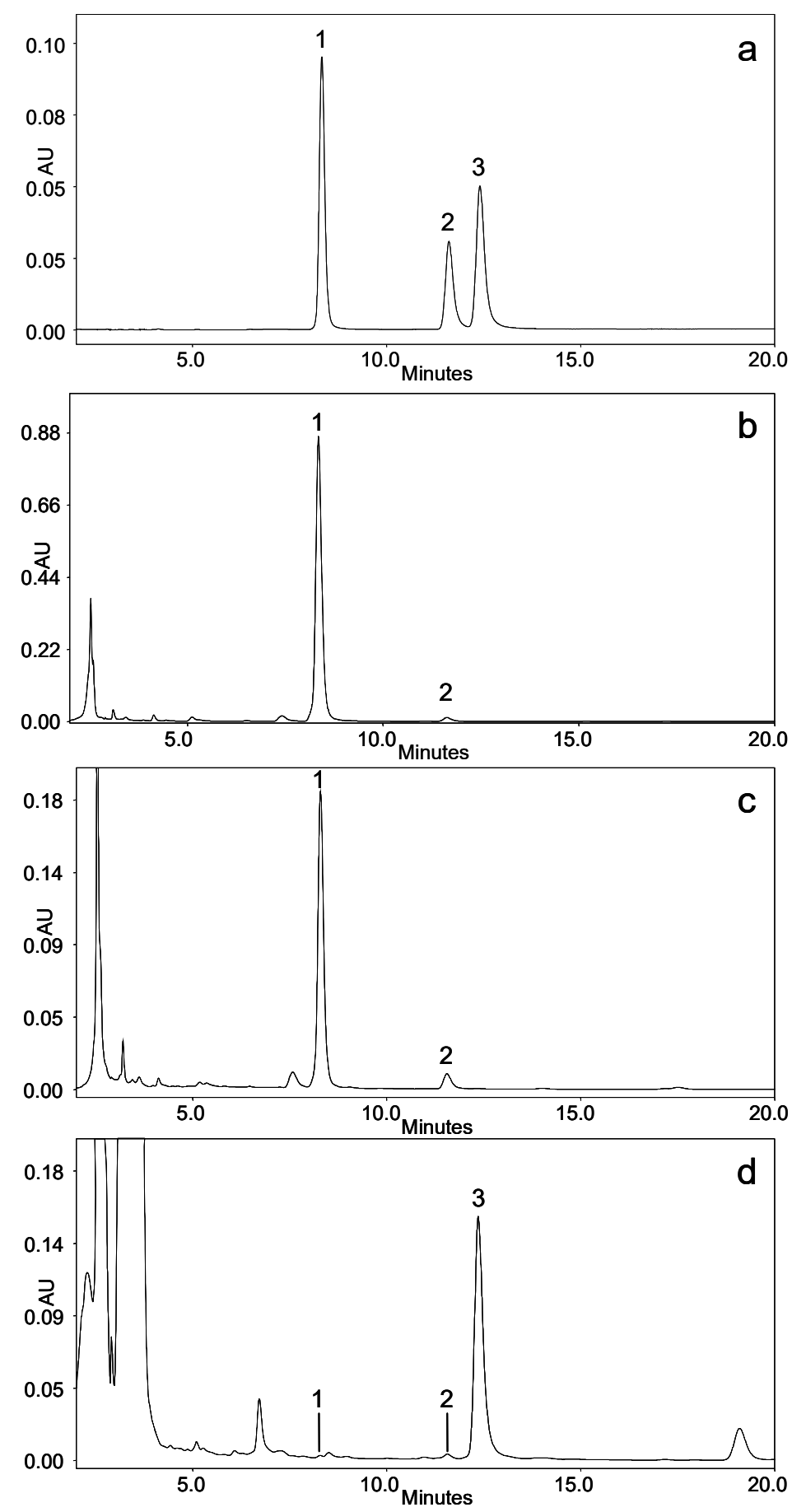

Figure 1. Chromatographic separation of cyanogenic glucosides: (a) mixture containing pure standards of amygdalin (1), prunasin (2) and sambunigrin (3), (b) plum kernel, (c) apple seed, (d) Sambucus nigra leaf.

The identification of the peaks was carried out by comparing the retention times and their UV-Vis spectra with those of the pure standards. In all the samples analyzed, the spectra of the compounds of interest did not present contamination and can be considered pure according to the purity criteria implemented in the Empower 3.0 program (purity angle $<$ purity threshold). 


\subsection{Extraction Optimization}

\subsubsection{Preselection of Extraction Conditions}

According to the concentrations described in the literature, a 1/100 ratio ( $0.1 \mathrm{~g}$ sample and $10 \mathrm{~mL}$ of solvent) was established as appropriate to perform the extraction quantitatively and efficiently in a single extraction. In a similar way, extraction conditions using UAE for 2 min with interval pulses of $20 \%$ and maximum amplitude $(100 \%)$ were chosen for the initial experimentation.

Under these conditions, extractions were carried out with different methanol/water mixtures $(100 \%, 70 \%, 50 \%, 30 \%, 10 \%$, and $0 \%)$ and water with $0.1 \%$ perchloric acid on two matrices: apple seed and leaves of $S$. nigra.

Figure 2 shows the extraction from apple seed with different solvents. As can be seen, the extraction of amygdalin in methanol mixtures was greater in a $50 \%$ mixture and at a higher proportion of water the recovery of amygdalin decreases and the content of prunasin and sambunigrin increases. It is important to highlight that sambunigrin has not been described in apple seed, but nonetheless, our results show that this compound can be formed and that the highest concentration of sambunigrin is detected when the solvent is water. In this sense, several authors have indicated that the degradation of amygdalin is closely linked to the extraction conditions $[24,25]$.

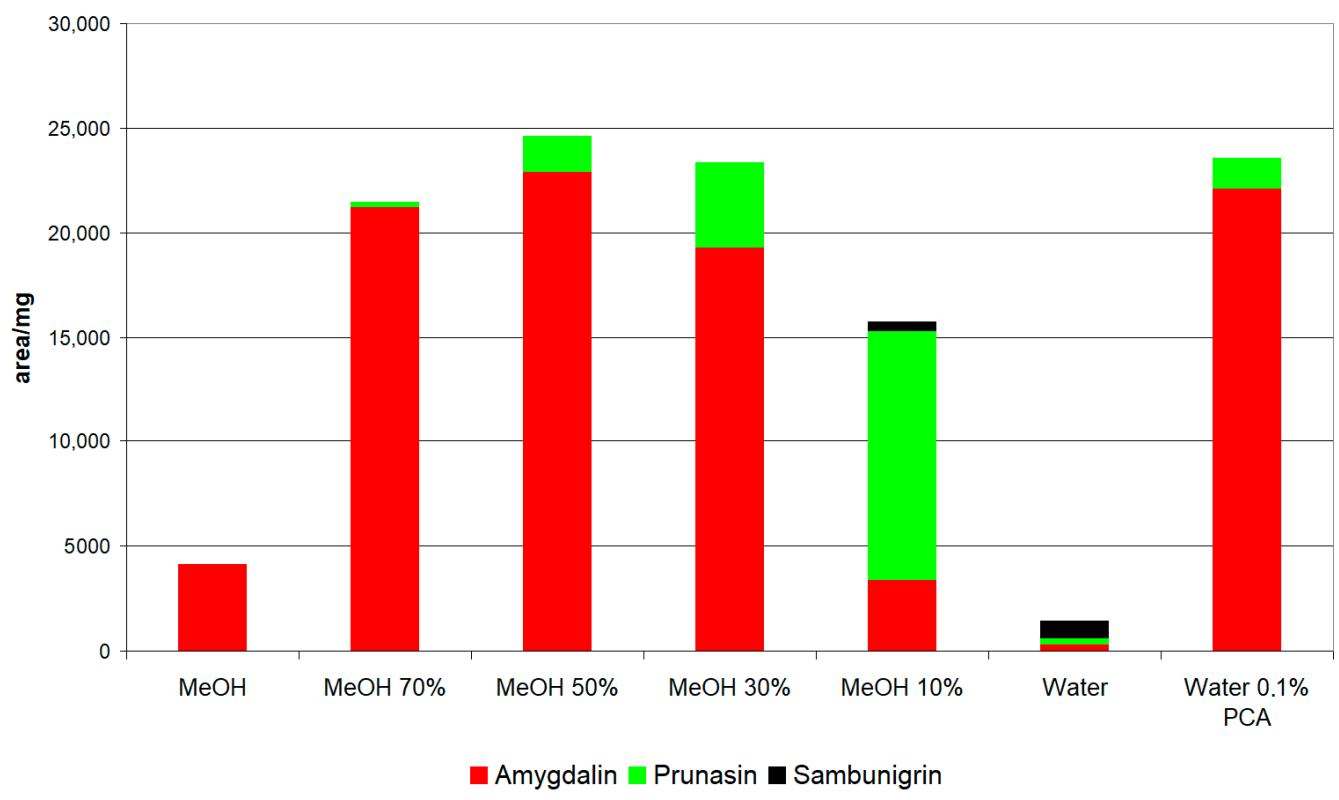

Figure 2. Extraction efficiency with different solvents in apple seed. PCA: perchloric acid.

When extraction is carried out with acidified water ( $0.1 \%$ perchloric), the content of amygdalin and prunasin is similar to the maximum detected for the methanol/water mixtures (Figure 2). Therefore, it was decided to carry out the extractions in water with $0.1 \%$ perchloric acid, which avoids the use of organic solvents.

No significant differences were detected in the $S$. nigra leaf extracts with the different solvents, the sambunigrin extraction being similar in all cases.

\subsubsection{Optimization of the Extraction Condition by UAE}

The extraction was optimized on the two matrices indicated above: apple seed and $S$. nigra leaf with $0.1 \mathrm{~g}$ of mass and $10 \mathrm{~mL}$ of water with $0.1 \%$ PCA.

The UAE conditions were optimized following a Box-Behnken design with three factors. Table 1 shows the extraction conditions and the area/mg values obtained for amygdalin in apple seed and sambunigrin in S. nigra leaf according to the BBD. 
Table 1. Coded and real values for the experimental factors and area/mg of amygdalin and sambunigrin according to the BBD.

\begin{tabular}{cccccc}
\hline Run & $\begin{array}{c}\text { Time } \\
(\mathbf{s})\end{array}$ & $\begin{array}{c}\text { Pulse } \\
\mathbf{( \% )}\end{array}$ & $\begin{array}{c}\text { Amplitude } \\
\mathbf{( \% )}\end{array}$ & $\begin{array}{c}\text { Amygdalin } \\
\text { (Area/mg) }\end{array}$ & $\begin{array}{c}\text { Sambunigrin } \\
\text { (Area/mg) }\end{array}$ \\
\hline 1 & $-1(20)$ & $0(60)$ & $-1(20)$ & 21,640 & 27,098 \\
2 & $-1(20)$ & $0(60)$ & $1(100)$ & 22,075 & 29,157 \\
3 & $1(60)$ & $0(60)$ & $-1(20)$ & 21,495 & 27,692 \\
4 & $1(60)$ & $0(60)$ & $1(100)$ & 23,625 & 29,619 \\
5 & $0(40)$ & $-1(20)$ & $-1(20)$ & 20,551 & 28,134 \\
6 & $0(40)$ & $-1(20)$ & $1(100)$ & 22,408 & 29,720 \\
7 & $0(40)$ & $1(100)$ & $-1(20)$ & 22,193 & 29,577 \\
8 & $0(40)$ & $1(100)$ & $1(100)$ & 23,123, & 30,537 \\
9 & $-1(10)$ & $-1(20)$ & $0(60)$ & 21,025 & 29,194 \\
10 & $1(60)$ & $-1(20)$ & $0(60)$ & 21,457 & 27,229 \\
11 & $-1(20)$ & $1(100)$ & $0(60)$ & 22,909 & 28,600 \\
12 & $1(60)$ & $1(100)$ & $0(60)$ & 23,246 & 30,188 \\
13 & $0(40)$ & $0(60)$ & $0(60)$ & 23,138 & 29,981 \\
14 & $0(40)$ & $0(60)$ & $0(60)$ & 23,770 & 29,791 \\
15 & $0(40)$ & $0(60)$ & $0(60)$ & 23,549 & 29,505 \\
16 & $0(40)$ & $0(60)$ & $0(60)$ & 23,040 & 30,088 \\
17 & $0(40)$ & $0(60)$ & $0(60)$ & 22,723 & 30,575 \\
\hline
\end{tabular}

Table 2 shows the results of fitting the second-order polynomial models for these variables. ANOVA indicated that both the models were statistically significant by the probability of the F-test at a level below 0.01 . Moreover, the probability values of the lack of fit tests were not significant in all cases $(p>0.10)$, indicating that the regression models are a good prediction of the experimental results. Satisfactory determination coefficients were obtained for both analytes (Table 2). Adjusted $\mathrm{R}^{2}, 0.859$ for amygdalin and 0.895 for sambunigrin, imply that the major percentage of variance of these variables is explained by the respective models, while the difference between these values and the predicted $R^{2}$ show that the models are not overfitted. The degree of precision, estimated as relative standard deviation (RSD) was very reliable, with values lower than $2 \%$.

Table 2. Statistics for models constructed from amygdalin and sambunigrin in terms of coded values.

\begin{tabular}{ccccc}
\hline & \multicolumn{2}{c}{ Amygdalin } & \multicolumn{2}{c}{ Sambunigrin } \\
\hline Model & & $* * *$ & & $* * *$ \\
Intercept & $23,244.29$ & & $29,970.60$ & $* * *$ \\
A-Time & 668.91 & n.s. & 816.43 & n.s. \\
B-Pulse & 271.72 & $* * *$ & 578.12 & $* * *$ \\
C-Amplitude & 753.95 & $*$ & - & - \\
AB & 423.64 & - & 888.15 & $* *$ \\
BC & - & $*$ & -455.76 & $*$ \\
A $^{2}$ & -562.82 & $*$ & -1145.16 & $*$ \\
B $^{2}$ & -472.28 & $* *$ & & n.s. \\
C $^{2}$ & -612.19 & n.s. & & 0.935 \\
Lack of Fit & & 0.921 & & 0.895 \\
R-Squared & & 0.859 & & 0.805 \\
Adjusted R & & 0.773 & & 1.21 \\
Predicted $\mathrm{R}^{2}$ & & 1.61 & & \\
RSD & & &
\end{tabular}

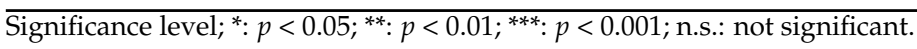

The physicochemical properties of amygdalin and sambunigrin are similar, since they are both saccharides (gentiobiose or glucose) linked to the same aglycone (mandelonitrile). Furthermore, they are soluble in water, so it seems reasonable that the models built for each of the analytes should be similar (Figures 3 and 4). Thus, for both analytes, similar models were obtained in which the significant first-order factors were time and amplitude 
but not the frequency with which the pulses are emitted (Table 2), while the differences are found in the second order terms (quadratic terms and interactions).

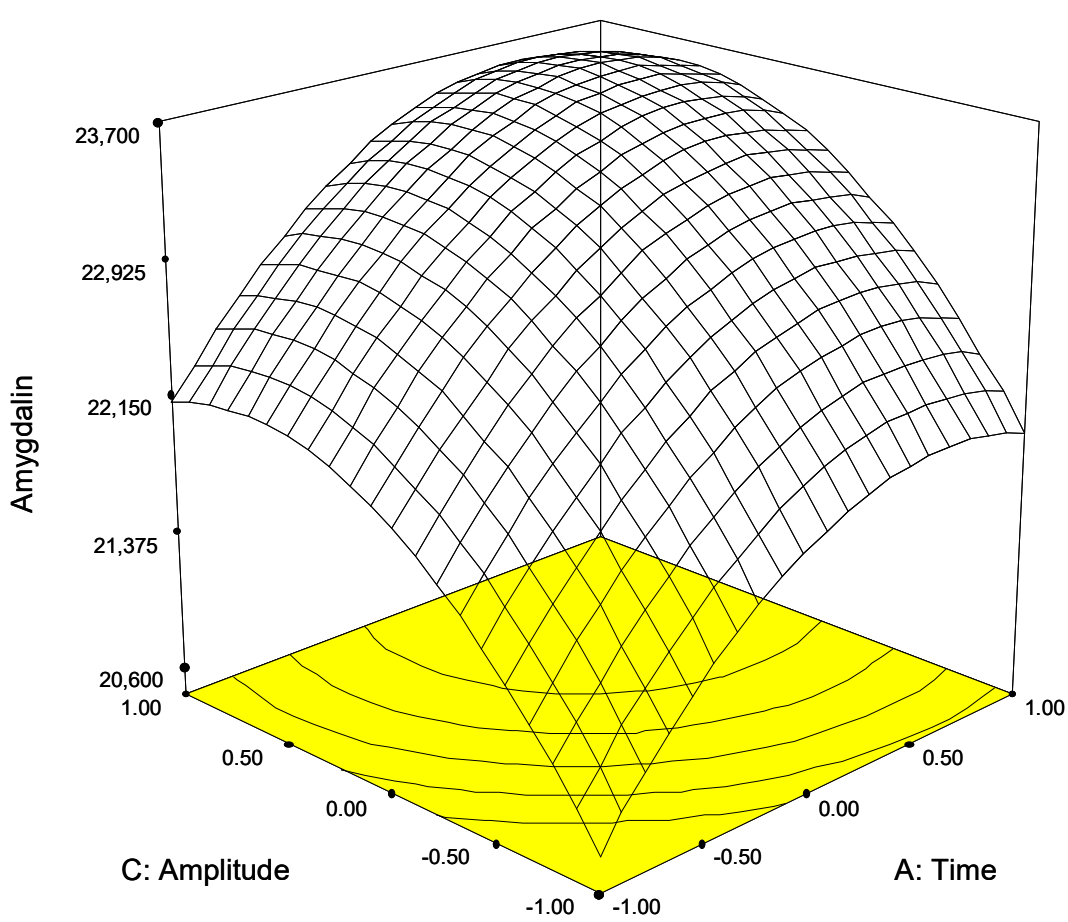

Figure 3. Response surface calculated from experimental data for amygdalin in apple seed slurry.

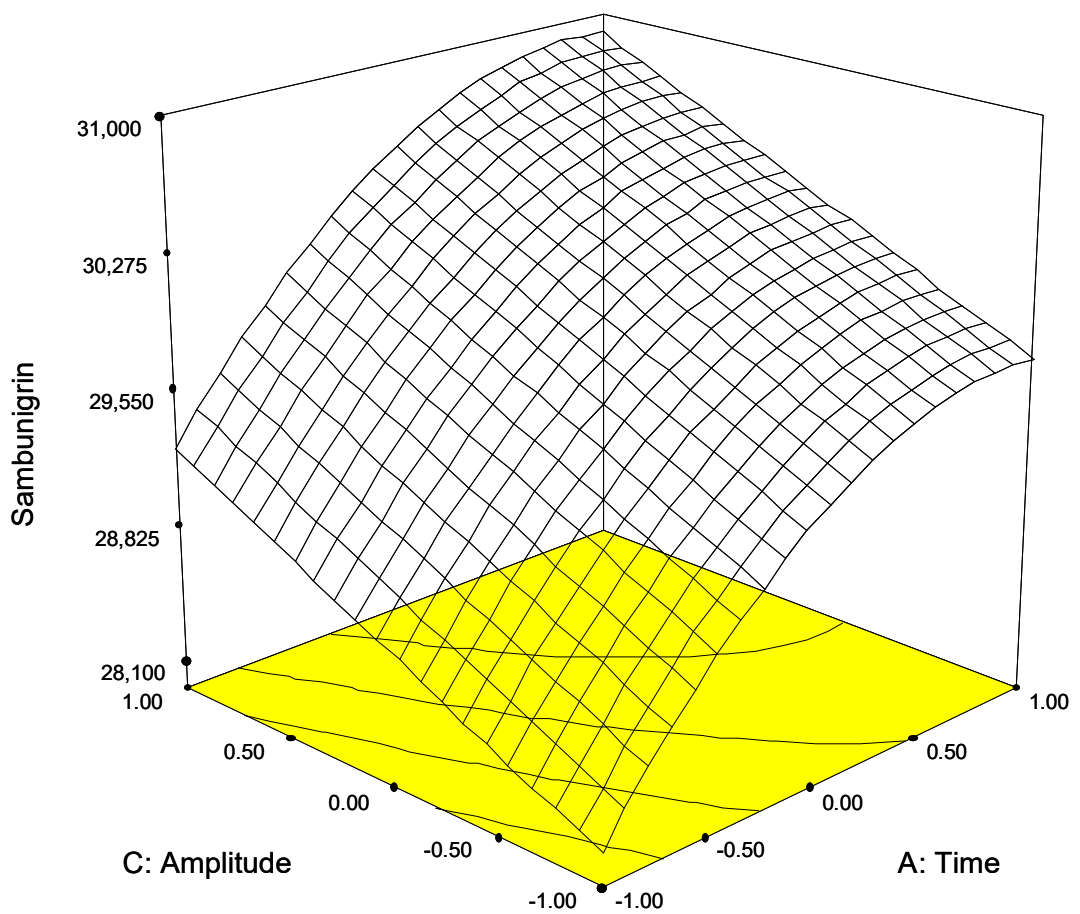

Figure 4. Response surface calculated from experimental data for sambunigrin in S. nigra leaf.

Since the mathematical models were similar for both variables, it was possible to establish - as a requirement for obtaining the optimal extraction results-that these were the conditions that simultaneously maximized the recovery of each analyte. Among the range of conditions satisfying this requisite, those selected were as follow: time $55 \mathrm{~s}$, pulse $70 \%$, and amplitude $80 \%$. 
Although the extraction conditions were optimized for a 1/100 sample/solvent ratio, the possibility of using different ratios in the matrices of interest was evaluated.

For this, the sample mass was varied between 0.01 and $0.5 \mathrm{~g}$, keeping a fixed volume of $10 \mathrm{~mL}$ as it was a recommended working volume for the sonotrode used (diameter $2 \mathrm{~mm}$ ). The behavior was different in the evaluated matrices. Thus, while in S. nigra leaves the response for sambunigrin was proportional to the mass in the entire range evaluated $(R=0.9995$, Supplementary Figure S1), in the case of apple seed, the efficiency of the extraction of amygdalin was linear only in the range $0.01-0.15 \mathrm{~g}(\mathrm{R}=0.994$, Figure 5). In addition, the lower extraction of amygdalin was accompanied by an increase in the percentage of prunasin and sambunigrin in the extracts, which indicates the degradation of amygdalin by hydrolysis of the $\beta$ (1-6) bond of gentiobiose and the formation of the two monoglycosidic epimers. Likewise, as can be seen in Figure 5, the sum of the three mandelonitrile CNGs ceases to be linear from a mass of $0.2 \mathrm{~g}$ (ratio 1/50, $\mathrm{r}=0.998$ ), which shows that, in addition to hydrolysis of the $\beta(1-6)$ bond of gentiobiose, subsequent hydrolysis of the glycosidic bonds of prunasin and sambunigrin takes place. Based on these results, it can be established that, in the case of apple seed, ratios greater than 1/66 may lead to underestimation of the content of amygdalin, as a result of its hydrolysis and the formation of the epimers prunasin and sambunigrin, while ratios greater than $1 / 50$ give rise to underestimated values for total mandelonitrile CNGs.

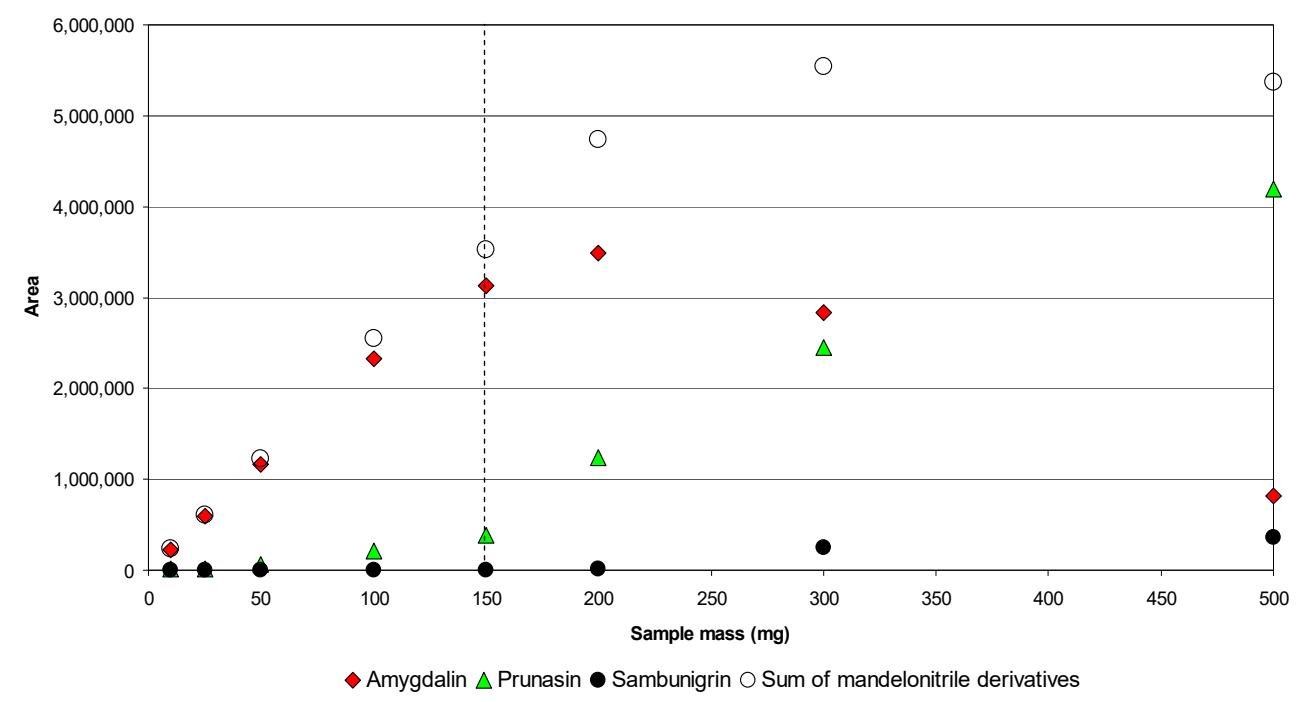

Figure 5. Extraction of amygdalin, prunasin, sambunigrin, and sum of mandelonitrile derivatives in apple seed at different sample mass.

\subsection{Validation Procedure}

The model was validated experimentally by two operators, on different days and conducting the tests independently (three replicates per operator/day).

Predicted and experimental values for variables are displayed in Table 3. The results were found within the predicted intervals, and the average accuracy of the values obtained against those predicted was $97 \%$ for amygdalin and $102 \%$ for sambunigrin.

\subsubsection{Precision, Accuracy, and Extract Stability}

Precision was calculated in two ways: repeatability and reproducibility. Repeatability (r), estimated for each analyst and compound ranged between $0.4-4.1 \%$ and reproducibility $(\mathrm{R})$, evaluated as the RSD between analysts was in all cases $\leq 2.3 \%$ (Table 3 ).

The accuracy of the method was evaluated in two ways: by exhaustive extraction of the plant material and in a recovery study conducted by spiking both matrixes with a known concentration of standard. 
Table 3. Validation of model (time: 55 s; pulse: 70\%; amplitude: 80\%) under reproducibility conditions.

\begin{tabular}{ccc}
\hline & $\begin{array}{c}\text { Amygdalin } \\
\text { (Area/mg) }\end{array}$ & $\begin{array}{c}\text { Sambunigrin } \\
\text { (Area/mg) }\end{array}$ \\
\hline Prediction & 23,770 & 30,664 \\
$95 \%$ CI low & 23,376 & 30,299 \\
$95 \%$ CI high & 24,165 & 31,028 \\
$95 \%$ PI low & 22,860 & 29,494 \\
$95 \%$ PI high & 24,681 & 31,533 \\
Operator 1 $(n=3)$ & 23,193 & 31,185 \\
Repeatability, r (RSD) & 1.0 & 4.1 \\
Operator 2 $(n=3)$ & 23,062 & 30,205 \\
Repeatability, r (RSD) & 2.0 & 1.9 \\
Reproducibility, R (RSD) & 0.4 & 2.3 \\
\hline CI: confidence interval. PI: prediction interval; RSD: relative standard deviation.
\end{tabular}

CI: confidence interval. PI: prediction interval; RSD: relative standard deviation.

Exhaustive extraction was carried out through four consecutive extractions from each sample involved in the validation (apple seed and S. nigra leaves). In this case, accuracy was estimated as area percentage (\%) in the first extraction. The values obtained showed a total accuracy of $95 \%$ for amygdalin in apple seed, and $92 \%$ for sambunigrin in S. nigra leaves (Figure 6).

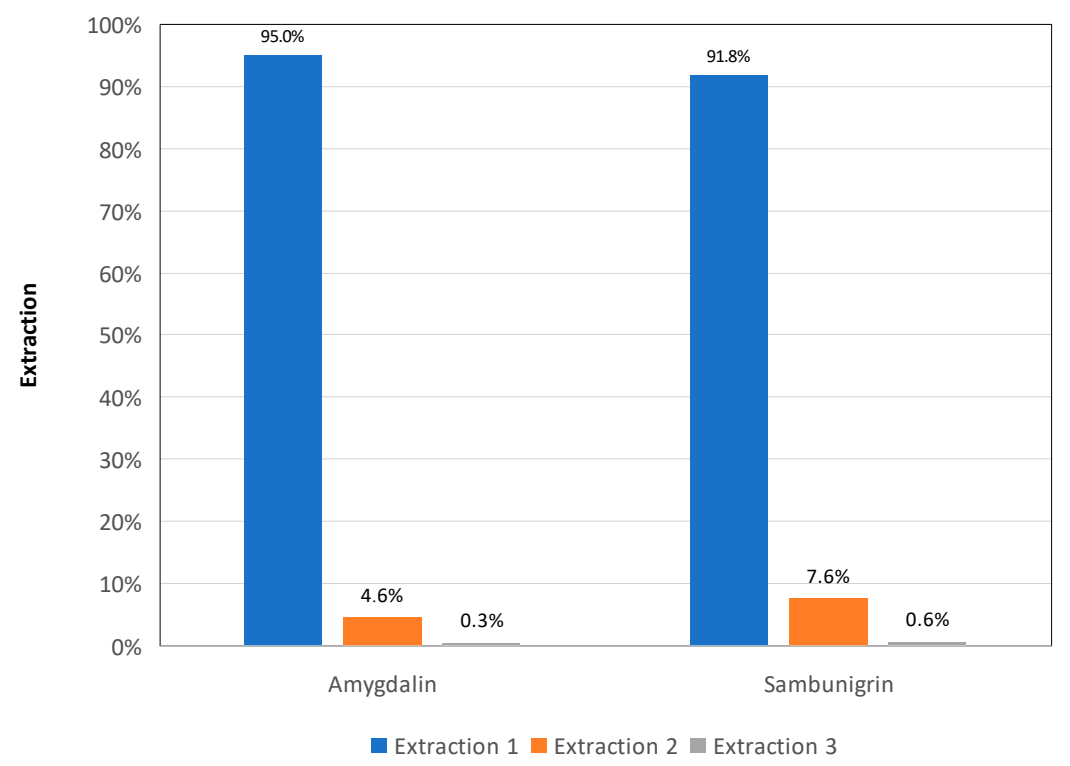

Figure 6. Result of the sequential extraction of amygdalin in apple seed and sambunigrin in S. nigra leaf and the percentage extracted in each one of them.

Recovery values between $100 \%$ and $104 \%$ for amygdalin in apple seed and between $90 \%$ and $92 \%$ for sambunigrin in S. nigra leaves were obtained. Furthermore, the comparison of the slopes of the calibration lines and the addition lines, by means of a $t$-student test for non-homogeneous variances, did not show significant differences. Supplementary Figure S2 shows the slopes of the calibration and addition lines for amygdalin and sambunigrin.

To evaluate the extracts' stability, they were maintained at $10^{\circ} \mathrm{C}$ and analyzed on 10 consecutive days. Both extracts were stable, with differences of less than $2 \%$ in the analytes of interest.

\subsubsection{Calibration Curves, LD, and LQ}

Calibration parameters are shown in Table 4. All of the compounds showed good linearity, with regression coefficients $>0.9997$ over three orders of magnitude. 
Table 4. Analytical characteristics of the calibration graphs of cyanogenic compounds.

\begin{tabular}{|c|c|c|c|c|c|c|c|c|}
\hline \multirow[b]{2}{*}{ Compound } & \multicolumn{4}{|c|}{ Calibration Curve } & \multicolumn{2}{|c|}{ Instrumental } & \multicolumn{2}{|c|}{ Method } \\
\hline & $\begin{array}{c}\text { Linear Range } \\
(\mathrm{mg} / \mathrm{L})\end{array}$ & Slope & Intercept & $\begin{array}{l}\text { Correlation } \\
\text { Coefficient }\end{array}$ & $\begin{array}{c}\text { LOD } \\
\left(10^{-3} \mathrm{mg} / \mathrm{L}\right)\end{array}$ & $\begin{array}{c}\text { LOQ } \\
\left(10^{-3} \mathrm{mg} / \mathrm{L}\right)\end{array}$ & $\begin{array}{c}\text { LOD } \\
\left(10^{-3} \mathrm{mg} / \mathrm{g}\right)\end{array}$ & $\begin{array}{c}\text { LOQ } \\
\left(10^{-3} \mathrm{mg} / \mathrm{g}\right)\end{array}$ \\
\hline Amygdalin $(n=11)$ & $0.24-480$ & 16224 & -8999 & 0.9999 & 6.5 & 21.7 & 0.7 & 2.2 \\
\hline Prunasin $(n=11)$ & $0.19-296$ & 20007 & -7906 & 0.9999 & 16.1 & 55.7 & 1.6 & 5.6 \\
\hline Sambunigrin $(n=10)$ & $0.20-390$ & 22257 & -2506 & 0.9998 & 28.8 & 96.0 & 2.9 & 9.6 \\
\hline
\end{tabular}

$n=$ number of points in calibration curve. LOD: limit of detection. LOQ: limit of quantitation.

In addition, method limits of detection and quantification (expressed as $\mu \mathrm{g} / \mathrm{g}$ ) were calculated from the instrumental limits of detection and quantification previously estimated [26] and taking the volume of extracts $(10 \mathrm{~mL})$ and the mass of samples used in extraction $(0.1 \mathrm{~g})$.

The method limit of detection ranged from $0.7 \mu \mathrm{g} / \mathrm{g}$ (amygdalin) to $2.9 \mu \mathrm{g} / \mathrm{g}$ (sambunigrin) and the method limit of quantification ranged from 2.2 to $9.6 \mu \mathrm{g} / \mathrm{g}$ for the same compounds.

Taking into account that the minimal lethal oral dose of hydrogen cyanide is estimated to be 0.5 to $3.5 \mathrm{mg} / \mathrm{kg}$ body weight [3], and the data reported by other authors [15-17], it can be concluded that the proposed method is sufficiently sensitive for the quantitative determination of these potential toxic phytochemicals.

\subsection{Cyanogenic Glycosides Contents in the Analyzed Samples}

\subsubsection{Rosacea}

The optimized and validated method was applied to analyze a set of different plant materials containing cyanogenic derivatives of mandelonitrile (Table 5). Rosaceae are one of the most interesting plant families in terms of the presence of mandelonitrile CNGs, especially amygdalin and prunasin, in their seeds and kernels. Therefore, the ability of the method to quantify these compounds in the seeds of apples, apple pomaces, and in the kernels of different species of the genus Prunus was evaluated.

The highest content of amygdalin was detected in plum kernels (cv. Reina Claudia Verde), with $57.3 \mathrm{mg} / \mathrm{g}$ dry sample, in contrast to the $3.6 \mathrm{mg} / \mathrm{g}$ detected in prune kernel. High levels of amygdalin were also detected in varieties of P. persicum (peach, flat peach, and nectarine) and in P. armeniaca (apricot), while the P. avium (cherry) samples showed the lowest amygdalin content in this genus, with values between 8.2 and $12.6 \mathrm{mg} / \mathrm{g}$ (Table 5).

The values reported for kernels of the analyzed species present wide variability, which can be attributed to different causes, such as the environmental conditions, conservation of the fruit or genetics. Thus, Bolarinwa et al. [16] reported values for plum kernels of between 0.44 and $17.49 \mathrm{mg} / \mathrm{g}$ for distinct varieties, pointing out that amygdalin is the major mandelonitrile CNG in green plums. In the present study, the values were found to be even higher. Several authors have described important differences between bitter and sweet varieties of apricot $[22,27,28]$ with values between undetectable and $70 \mathrm{mg} / \mathrm{g}$, the content of amygdalin being higher in bitter varieties than in sweet ones. High ranges of variability have also been found for amygdalin in cherry, with values between 0.732 [15] and $65 \mathrm{mg} / \mathrm{g}$ [29], which places the content of the samples analyzed in this work $(8.2-12.6 \mathrm{mg} / \mathrm{g})$ in the middle range. Lee et al. [30] detected an amygdalin content of $23.1 \mathrm{mg} / \mathrm{g}$ in peaches, similar to our results for the different varieties of P. persicum, which are significantly higher than those reported by Bolarinwa et al. [16] for nectarines and peaches, $0.15 \mathrm{mg}$ and $6.81 \mathrm{mg} / \mathrm{g}$ respectively.

In the present study, values for amygdalin that were slightly higher than those detected in cherries were detected in the apple seed samples analyzed, ranging between 13.4 and $18.6 \mathrm{mg} / \mathrm{g}$. Likewise, a wide distribution was reported for the content of amygdalin in apple seeds, with values between 0.24 and $0.70 \mathrm{mg} / \mathrm{g}$ measured by AmayaSalcedo [14], 0.95-3.91 mg/g by Bolarinawa et al. [31], 1.19-1.63 mg/g of fresh weight by Senica et al. [32], and $13 \mathrm{mg} / \mathrm{g}$ by Opyd et al. [33]. Senica et al. [34] evaluated the 
cyanogenic glycosides in Golden Delicious seeds from four countries in Eastern Europe, observing that their contents vary greatly due to environmental conditions and with the time of conservation of the apples in a controlled atmosphere; the amygdalin contents of apple seeds ranged from 0.52 to $0.85 \mathrm{mg} / \mathrm{g}$ fresh weight at harvest time.

Table 5. Cyanogenic mandelonitrile derivatives in distinct plant materials ( $\mathrm{mg} / \mathrm{g}$ dry matter).

\begin{tabular}{|c|c|c|c|}
\hline & Amygdalin & Prunasin & Sambunigrin \\
\hline \multicolumn{4}{|l|}{ Rosaceae } \\
\hline \multicolumn{4}{|l|}{ Kernels } \\
\hline$\overline{\text { Cherry-1 (P. avium) }}$ & 12.6 & 1.8 & n.d. \\
\hline Cherry-2 (P. avium) & 11.8 & 2.2 & n.d. \\
\hline Cherry cv picota (P. avium) & 8.2 & 1.1 & n.d. \\
\hline Apricot (P. armeniaca) & 45.0 & 1.5 & n.d. \\
\hline Peach (P. persica) & 43.3 & 0.6 & n.d. \\
\hline $\begin{array}{l}\text { Flat peach (P. persica var. } \\
\text { platycarpa) }\end{array}$ & 23.7 & 2.0 & n.d. \\
\hline $\begin{array}{l}\text { Nectarine ( } P \text {. persica var. } \\
\text { nucipersica) }\end{array}$ & 32.7 & 1.3 & n.d. \\
\hline $\begin{array}{l}\text { Plum cv Reina Claudia } \\
\text { verde }(P . \text { domestica })\end{array}$ & 57.3 & 0.9 & n.d. \\
\hline Prune kernel (P. domestica) & 3.6 & 0.5 & 0.1 \\
\hline \multicolumn{4}{|l|}{ Apple seed } \\
\hline Golden delicious & 13.6 & 0.9 & 0.1 \\
\hline Durona de Tresali & 14.9 & 0.3 & n.d. \\
\hline Seed from apple pomace- 1 & 13.4 & 0.3 & n.d. \\
\hline Seed from apple pomace- 2 & 13.8 & 0.3 & n.d. \\
\hline Seed from apple pomace- 3 & 15.0 & 0.5 & n.d. \\
\hline Seed from apple pomace- 4 & 18.6 & 0.8 & n.d. \\
\hline Seed from apple pomace- 5 & 16.4 & 1.1 & n.d. \\
\hline \multicolumn{4}{|l|}{ Apple pomace flour } \\
\hline Apple pomace-1 & 0.1 & n.d. & n.d. \\
\hline Apple pomace-2 & 0.1 & n.d. & n.d. \\
\hline \multicolumn{4}{|l|}{ Sambucus nigra } \\
\hline Young leaf & 0.2 & 0.4 & 16.2 \\
\hline Old leaf & 0.1 & 0.8 & 20.7 \\
\hline Flower-1 & n.d. & n.d. & 0.6 \\
\hline Flower-2 & n.d. & n.d. & 0.4 \\
\hline Flower bud & n.d. & n.d. & 0.3 \\
\hline Stalk & n.d. & n.d. & 1.7 \\
\hline Fruit-1 (elderberry) & n.d. & n.d. & 0.4 \\
\hline Fruit-2 (elderberry) & n.d. & n.d. & 0.3 \\
\hline
\end{tabular}

On the other hand, both the apple seeds and the samples of the genus Prunus presented lower amounts of prunasin than amygdalin, in many cases less by an order of magnitude, with values between $0.3 \mathrm{mg} / \mathrm{g}$ in several apple seeds and $2.2 \mathrm{mg} / \mathrm{g}$ in a cherry sample (Table 5). These results are in agreement with those reported in the bibliography, although the number of references is small $[15,22]$. However, Senica et al. [34] showed that the main cyanogenic glycoside in Golden Delicious seeds from Azerbaijan and Russia was prunasin $(1.32 \mathrm{mg} / \mathrm{g}$ and $0.91 \mathrm{mg} / \mathrm{g})$.

Different studies have been carried out on the composition and properties of apple pomace, revealing that it is an interesting raw material due its content in nutrients, phytochemicals, and functional components [35,36]. Apple pomace produced by the cider making industry contains apple seeds in variable quantities, which can account for up to $5 \%$ of the total weight [37]. Regarding the apple pomace samples analyzed (Table 5), the content of amygdalin $(0.1 \mathrm{mg} / \mathrm{g})$ was especially low and could generate $5.9 \mu \mathrm{g}$ cyanide equivalents per gram of apple pomace. Acute cyanide toxicity can occur in humans at 
doses between 0.5 and $3.5 \mathrm{mg} / \mathrm{kg}$ body weight [3], so the results for the amygdalin content of apple pomaces guarantee the safe use of this by-product in food formulations.

\subsubsection{Sambucus nigra}

The species S. nigra has been described as potentially toxic due to the content of sambunigrin in its different parts. In this case, the quantification method identified the highest content in the leaves of the species, between 16.2 and $20.7 \mathrm{mg} / \mathrm{g}$ dry matter, while the flowers, stalks, and fruits presented significantly lower values of sambunigrin (Table 5). Values for sambunigrin reported by other authors range between $1.0 \mathrm{mg} / \mathrm{g}$ dry matter and $0.03-0.21 \mathrm{mg} / \mathrm{g}$ fresh sample $[17,38]$. On the contrary, in this species, the contents of amygdalin and prunasin were unimportant in all parts except the leaves.

\section{Materials and Methods}

\subsection{Sample Material and Preparation of the Extracts}

The fruits (cherry, apricot, peach, flat peach, nectarine, plum) came from the local market. The stones were removed and broken to obtain the intact seeds.

Five apple pomace samples, obtained from the local cider industry, were freeze-dried. The seeds of the apple pomaces were separated manually.

Leaves, flowers, branches, and fruits of $S$. nigra were collected from wild specimens of this species located at the SERIDA facilities.

All samples were freeze-dried and stored under vacuum until the moment of their analysis.

Freeze-dried samples were milled at the time of extraction in a mortar and the powders were sieved through a standard sieve (number 18, corresponding to a sieve open ring size of $1.00 \mathrm{~mm})$.

\subsection{Reagents and Standards}

Amygdalin (CAS number: 29883-15-6) was purchased from Sigma-Aldrich (St. Louis, MO). Prunasin (CAS number: 99-18-3) and sambunigrin (CAS number: 99-19-4) were supplied by LGC standards (Teddington, Middlesex, UK). Methanol HPLC grade was purchased from JT Baker (Deventer, Holland). Water was purified using a Milli-Q system from Millipore (Bedford, MA, USA).

\subsection{Chromatographic Separation and Identification}

Analyses were performed with a Waters system, equipped with a 717 plus autosampler, provided with a temperature controller, a model 600 pump, a diode array detector (DAD 2996) and Empower software v.3.0 data module. Separation of polyphenols was carried out on a reversed-phase Macherey-Nagel Nucleosil 120 C18 column $(250 \times 4.6 \mathrm{~mm}$ I.D, $3 \mu \mathrm{m}$ ) from Fisher Scientific (Loughborough, UK). The column was thermostated at $25^{\circ} \mathrm{C}$ and the injection volume was $20 \mu \mathrm{L}$. The elution solvent was methanol/water $(25 / 75)$ in isocratic mode at $1 \mathrm{~mL} / \mathrm{min}$. The UV-Vis spectra were acquired from $190 \mathrm{~nm}$ to $400 \mathrm{~nm}$ with a sampling rate of 1.0 and the highest scanning resolution $(1 \mathrm{~nm})$.

The identity of CNGs was ascertained using data from DAD, by comparison and combination of their retention times and UV-Vis spectra and confirmed with authentic standards. Quantification was performed by HPLC-DAD according to an external standard method at $214 \mathrm{~nm}$.

\subsection{Experimental Design and Extraction Optimization}

Ultrasonic assisted extraction (UAE) was employed to extract CNGs. The samples were extracted in a water bath at $20^{\circ} \mathrm{C}$. The extraction was carried out with an UP200Ht ultrasonic homogenizer (Hielscher, Teltow, Germany) equipped with a $2 \mathrm{~mm}$ diameter sonotrode at a frequency of $26 \mathrm{kHz}$ and $200 \mathrm{~W}$ power input. The extraction was carried out in pulse mode. 
A Box-Behnken design (BBD) was applied to maximize the extraction of CNGs. Three factors in the design were studied at three levels $(-1,0$, and +1$)$ and five center points to allow efficient estimation of the first- and second-order coefficients. The factors considered to determine the conditions for maximizing extraction of $\mathrm{CNG}$ compounds were amplitude of sonication (20,60, and 100\%), time of extraction $(20,40$, and 60 s), and duty cycle $(20,60$ and $100 \%)$.

According to this experimental design (BBD), 17 extracts were carried out. The experimental data were examined using response surface methodology (RSM). The three variables mentioned above were tested for possible linear and quadratic models to find the model with the best fit. To compute the predicted responses (Y) a polynomial Equation (1):

$Y=b_{0}+b_{1} X_{1}+b_{2} X_{2}+b_{3} X_{3}+b_{12} X_{1} X_{2}+b_{13} X_{1} X_{3}+b_{23} X_{2} X_{3}+b_{123} X_{1} X_{2} X_{3}+b_{11} X_{1}{ }^{2}+b_{22} X_{2}{ }^{2}+b_{33} X_{3}^{2}$

for each variable was estimated: $X_{1}=$ extraction time, $X_{2}=$ amplitude, $X_{3}=$ duty-cycle, $b_{0}$ is the offset term, $b_{1}, b_{2}$ and $b_{3}$ the first order coefficients, $b_{11}, b_{22}$, and $b_{33}$ the second order coefficients, and $b_{12}, b_{13}, b_{23}$, and $b_{123}$ the interaction coefficients.

Design Expert 7.0.0 Software (Stat-Ease, Inc., Minneapolis, MN, USA) was used to analyze the results.

\subsection{UAE Conditions}

The optimum conditions were as follow: amplitude $80 \%$ ( $16 \mathrm{~W}$ power output), extraction time $55 \mathrm{~s}$, duty cycle $70 \%$, sample mass $0.1 \mathrm{~g}$ and extract volume $10 \mathrm{~mL}$.

After sonication, the samples were immediately filtered through a $0.45 \mu \mathrm{m}$ cellulose acetate syringe prior HPLC analysis. Two extractions were carried out for each sample.

\subsection{Validation Procedure}

Parameters checked for method validation were selectivity, examining chromatographic blanks and purity criteria of analytes peaks by Empower 3.0; precision, was calculated (RSD \%) as repeatability and reproducibility. Accuracy of the method was evaluated by exhaustive extraction (four consecutive extractions of the plant material) and a recovery study conducted by spiking with a known concentration of standard at three levels (low, medium, and high).

The linearity of the response of detector was determined by the square correlation coefficients of the calibration curves generated by injection of standard solutions at concentrations including the range expected in real samples. Instrumental limit of detection and instrumental limit of quantification were estimated as $3 \times \mathrm{Sa} / \mathrm{m}$ and $10 \times \mathrm{Sa} / \mathrm{m}$, respectively, from the residuals of calibration curves at low concentrations, where $\mathrm{Sa}$ is the standard deviation of calibration curve intercept values and $\mathrm{m}$ is the slope of the calibration curve $\mathrm{y}=\mathrm{a}+\mathrm{mx}$.

\section{Conclusions}

A method for accurately quantifying the cyanogenic derivatives of mandelonitrile, based on extraction with high-power ultrasound (UAE), with acidified water as solvent and quantification by HPLC-DAD was developed. In this study, the extraction time was significantly reduced when compared to other methods proposed, which is especially important to avoid degradation of amygdalin during the extraction phase. Special attention should be paid to the sample/solvent ratio in samples with potential $\beta$-glucosidase activity, such as apple seeds, to avoid the degradation of the cyanogenic glycosides (CNGs) by enzymatic action and, furthermore, ratios greater than 1/50 give rise to underestimated values for all of the mandelonitrile CNGs. The method was successfully applied to characterize cyanogenic derivatives of mandelonitrile in 18 samples of the Rosaceae family and 8 plant materials of Sambucus nigra. 
Supplementary Materials: The following are available online. Figure S1: Extraction of sambunigrin in S. nigra leaf at different sample mass. Figure S2: Calibration ( $(\boldsymbol{\Lambda})$ and addition ( $\boldsymbol{\square})$ lines for amygdalin and sambunigrin.

Author Contributions: Conceptualization, writing-original draft preparation, formal analysis, R.R.M.; methodology, investigation, R.R.M. and B.S.V., resources, visualization, writing-review and editing B.S.V. All authors have read and agreed to the published version of the manuscript.

Funding: Financial support for this work comes from project PID2020-11873RR-C21 financed by MCIN/AEI/10.13039/501100011033.

Institutional Review Board Statement: Not applicable.

Informed Consent Statement: Not applicable.

Data Availability Statement: Not applicable.

Conflicts of Interest: The authors declare no conflict of interest.

Sample Availability: Samples of the compounds are not available from the authors.

\section{References}

1. Cuny, M.; La Forgia, D.; Desurmont, G.A.; Glauser, G.; Benrey, B. Role of cyanogenic glycosides in the seeds of wild lima bean, Phaseolus lunatus: Defense, plant nutrition or both? Planta 2019, 250, 1281-1292. [CrossRef]

2. Del Cueto, J.; Ionescu, I.A.; Pičmanová, M.; Gericke, O.; Motawia, M.S.; Olsen, C.E.; Campoy, J.A.; Dicenta, F.; Møller, B.L.; Sánchez-Pérez, R. Cyanogenic Glucosides and Derivatives in Almond and Sweet Cherry Flower Buds from Dormancy to Flowering. Front. Plant Sci. 2017, 8, 800. [CrossRef] [PubMed]

3. Shibamoto, T.; Bjeldanes, L.F. Introduction to Food Toxicology, 2nd ed.; Academic Press: New York, NY, USA, 2009 ; pp. 134-138. [CrossRef]

4. Gleadow, R.M.; Woodrow, I.E. Constraints on effectiveness of cyanogenic glycosides in herbivore defense. J. Chem. Ecol. 2002, 28, 1301-1313. [CrossRef] [PubMed]

5. EFSA Panel on Contaminants in the Food Chain (CONTAM). Acute health risks related to the presence of cyanogenic glycosides in raw apricot kernels and products derived from raw apricot kernels. EFSA J. 2016, 14, 4424.

6. Regulation (EC) No. 1881/2006 of the European Parliament and the Council of 19 December 2006 Setting Maximum Levels for Certain Contaminants in Foodstuffs; OJ L 364; European Union: Maastricht, The Netherlands, 2006; pp. 5-24.

7. Regulation (EC) No. 1334/2008 of the European Parliament and of the Council of 16 December 2008 on Flavourings and Certainfood Ingredients with Flavouring Properties for Use in and on Foods and Amending Council Regulation (EEC) No. 160/1, Regulations (EC) No. 2232/96 and (EC) No. 110/2008 and Directive 2000/13/EC; OJ L 354; European Union: Maastricht, The Netherlands, 2008; pp. 34-50.

8. Regulation (EC) No. 110/2008 of the European Parliament and of the Council of 15 January 2008 on the Definition, Description, Presentation, Labelling and the Protection of Geographical Indications of Spirit Drinks and Repealing Council Regulation (EEC)No. 1576/89; OJ L 39; European Union: Maastricht, The Netherlands, 2008; p. 16.

9. The Stationery Office. Available online: https://www.legislation.gov.uk/uksi/2012/1916/pdfs/uksi_20121916_en.pdf (accessed on 30 November 2021).

10. Bundesministerium de Justiz und für Verbraucherschutz. Available online: http://www.gesetze-im-internet.de/amg_1976 /BJNR024480976.html (accessed on 30 November 2021).

11. Gazzete. Available online: http://www.foodstandards.gov.au/code/changes/gazette/Documents/GazetteNo159WebVersion. pdf (accessed on 30 November 2021).

12. Jaszczak-Wilke, E.; Polkowska, Z.; Koprowski, M.; Owsianik, K.; Mitchell, A.; Bałczewski, P. Amygdalin: Toxicity, Anticancer Activity and Analytical Procedures for Its Determination in Plant Seeds. Molecules 2021, 26, 2253. [CrossRef]

13. Ballhom, D.J. Cyanogenic glycosides in nuts and sedds. In Nuts and Seeds in Health and Disease Prevention; Preedy, V.R., Watson, R.R., Patel, V.D., Eds.; Acedemic Press: San Diego, CA, USA, 2011; pp. 129-136.

14. Castaño, J.A.G.; Salcedo, J.C.A.; Gónzalez, O.E.C. Solid-to-liquid extraction and HPLC/UV determination of amygdalin of seeds of apple (Malus pumila Mill): Comparison between traditional-solvent and microwave methodologies. Acta Agron. 2018, 67, 381-388. [CrossRef]

15. Senica, M.; Stampar, F.; Veberic, R.; Mikulic-Petkovsek, M. Transition of phenolics and cyanogenic glycosides from apricot and cherry fruit kernels into liqueur. Food Chem. 2016, 203, 483-490. [CrossRef]

16. Bolarinwa, I.F.; Orfila, C.; Morgan, M.R.A. Amygdalin content of seeds, kernels and food products commercially-available in the UK. Food Chem. 2014, 152, 133-139. [CrossRef] [PubMed]

17. Senica, M.; Stampar, F.; Mikulic-Petkovsek, M. Harmful (cyanogenic glycoside) and beneficial (phenolic) compounds in different Sambucus species. J. Berry Res. 2019, 9, 395-409. [CrossRef] 
18. Haque, M.R.; Bradbury, J.H. Total cyanide determination of plants and foods using the picrate and acid hydrolysis methods. Food Chem. 2002, 77, 107-114. [CrossRef]

19. Cho, H.-J.; Do, B.-K.; Shim, S.-M.; Kwon, H.; Lee, D.-H.; Nah, A.-H.; Choi, Y.-J.; Lee, S.-Y. Determination of Cyanogenic Compounds in Edible Plants by Ion Chromatography. Toxicol. Res. 2013, 29, 143-147. [CrossRef]

20. Berenguer-Navarro, V.; Giner-Galván, R.M.; Grané-Teruel, N.; Arrazola-Paternina, G. Chromatographic determination of cyanoglycosides prunasin and amygdalin in plant extracts using a porous graphitic carbon column. J. Agric. Food Chem. 2002, 50, 6960-6963. [CrossRef] [PubMed]

21. Appenteng, M.; Krueger, R.; Johnson, M.; Ingold, H.; Bell, R.; Thomas, A.; Greenlief, C. Cyanogenic Glycoside Analysis in American Elderberry. Molecules 2021, 26, 1384. [CrossRef] [PubMed]

22. Deng, P.; Cui, B.; Zhu, H.; Phommakoun, B.; Zhang, D.; Li, Y.; Zhao, F.; Zhao, Z. Accumulation Pattern of Amygdalin and Prunasin and Its Correlation with Fruit and Kernel Agronomic Characteristics during Apricot (Prunus armeniaca L.) Kernel Development. Foods 2021, 10, 397. [CrossRef]

23. Madrera, R.R.; Valles, B.S. Development and validation of ultrasound assisted extraction (UAE) and HPLC-DAD method for determination of polyphenols in dry beans (Phaseolus vulgaris). J. Food Compos. Anal. 2019, 85, 103334. [CrossRef]

24. Wahab, M.F.; Breitbach, Z.S.; Armstrong, D.W.; Strattan, R.; Berthod, A. Problems and Pitfalls in the Analysis of Amygdalin and Its Epimer. J. Agric. Food Chem. 2015, 63, 8966-8973. [CrossRef]

25. Yu, H.-L.; Xu, J.-H.; Lu, W.-Y.; Lin, G.-Q. Identification, purification and characterization of $\beta$-glucosidase from apple seed as a novel catalyst for synthesis of O-glucosides. Enzym. Microb. Technol. 2007, 40, 354-361. [CrossRef]

26. Miller, J.N. Basic Statistical Methods for Analytical Chemistry Part 2. Calibration and Regression Methods. A Review. Analyst 1991, 116, 3-14. [CrossRef]

27. Akinci Yildirim, F.; Atilla Askin, M. Variability of amygdalin content in seeds of sweet and bitter apricot cultivars in Turkey. Afr. J. Biotechnol. 2010, 9, 6522-6524.

28. Femenia, A.; Rossello, C.; Mulet, A.; Canellas, J. Chemical Composition of Bitter and Sweet Apricot Kernels. J. Agric. Food Chem. 1995, 43, 356-361. [CrossRef]

29. Voldřich, M.; Kyzlink, V. Cyanogenesis in Canned Stone Fruits. J. Food Sci. 1992, 57, 161-162. [CrossRef]

30. Lee, S.-H.; Oh, A.; Shin, S.-H.; Kim, H.-N.; Kang, W.-W.; Chung, S.-K. Amygdalin Contents in Peaches at Different Fruit Development Stages. Prev. Nutr. Food Sci. 2017, 22, 237-240. [CrossRef]

31. Bolarinwa, I.F.; Orfila, C.; Morgan, M.R. Determination of amygdalin in apple seeds, fresh apples and processed apple juices. Food Chem. 2015, 170, 437-442. [CrossRef] [PubMed]

32. Senica, M.; Stampar, F.; Veberic, R.; Mikulic-Petkovsek, M. Fuit seeds of the Rosaceae family: A waste, new life, or a danger to human health? J. Agric. Food Chem. 2017, 65, 10621-10629. [CrossRef]

33. Opyd, P.M.; Jurgoński, A.; Juśkiewicz, J.; Milala, J.; Zduńczyk, Z.; Król, B. Nutritional and Health-Related Effects of a Diet Containing Apple Seed Meal in Rats: The Case of Amygdalin. Nutrients 2017, 9, 1091. [CrossRef]

34. Senica, M.; Stampar, F.; Veberic, R.; Mikulic-Petkovsek, M. Cyanogenic glycosides and phenolics in apple seeds and their changes during long term storage. Sci. Hortic. 2019, 255, 30-36. [CrossRef]

35. Madrera, R.R.; Bedriñana, R.P.; Valles, B.S. Enhancement of the nutritional properties of apple pomace by fermentation with autochthonous yeasts. LWT Food Sci. Technol. 2017, 79, 27-33. [CrossRef]

36. García, Y.D.; Valles, B.S.; Lobo, A.P. Phenolic and antioxidant composition of by-products from the cider industry: Apple pomace. Food Chem. 2009, 117, 731-738. [CrossRef]

37. Madrera, R.R.; Valles, B.S. Characterization of apple seeds and their oils from the cider-making industry. Eur. Food Res. Technol. 2018, 244, 1821-1827. [CrossRef]

38. Senica, M.; Stampar, F.; Veberic, R.; Mikulic-Petkovsek, M. The higher the better? Differences in phenolics and cyanogenic glycosides in Sambucus nigra leaves, flowers and berries from different altitudes. J. Sci. Food Agric. 2016, 97, 2623-2632. [CrossRef] 